reactor physics, materials and engineering departmonts of the establishment are almost entirely concorned with the Orgel reactor project. The Orgel reactor is fuelled by natural uranium (in the form of ceramic compounds or alloys), heavy water moderated and cooled by high-boiling organic compounds. The structural materials consist of special preparations of light metals. Section 3 of the report by J. C. Leny and S. Orlowski describes in detail the Orge project and the associated Orgel critical experiment and the Essor test reactor, which is now being constructed and which is expected to go critical at the end of 1966 .

The Central Bureau of Nuclear Measurements, the establishment at Geel, is envisaged to become, in the nuclear field, a bureau of standards similar to the well. known national standards laboratories. The laboratories of the Central Bureau as planned in 1960 are now nearing completion; and by the end of 1964 the Bureau will have received all its heavy equipment. The pulsed $3-\mathrm{MeV}$ Van de Graaff accelerator with a Mobley bunching system is in operation and the pulsed electron linear accelerator, of the travelling-wave type ( $S$ band, approx. 10-cm wave-length), is now being installed. The duties of the Bureau include not only the preparation and conservation of primary standards and their intercomparison with those of other laboratories, but also the improvement of standards, instruments and methods of measurement in addition to the accurate measurement of nuclear data. A full description of the Bureau together with its equipment for fissile and stable isotopes is given in Section 2 of the report.
Petten is a general-purpose establishment, the main function of which at present is to operate the test reactor ( $H F R$ ) provided by the Dutch Government through the Reactor Centrum Nederland. The establishment is responsible also for the management of certain other important associations-BR2, Dragon, $T H T R$ and Kema-and a general programme of study related to them. The reactor $H F R$ is virtually identical with the reactor $O R R$ at Oak Ridge, and, consequently, close relations exist between the Petten and Oak Ridge establishments with regard to high-temperature reactors.

The specialized establishment, the Transuranium Institute at Karlsruhe, now in the course of construction on a site assigned to Euratom by the Gesellschaft für Kernforschung, is to be devoted to the non-military uses of plutonium in the nuclear energy industry. The laboratory will be brought gradually into use from about mid-1964 and is expected to be complete by 1966.

In addition to the sections dealing with the research establishments, there are sections dealing with thermonuclear research, radiobiology, radiation protection, industrial development of power reactors, marine reactors, the Euratom-United States joint programme, and the activities of the Eurisotop Bureau. The total personnel employed by Euratom on January 1, 1963, was 1,910, of which some 1,500 were members of the research establishments. The total is expected to rise to 3,200 by the end of the five-year programme in 1967.

\title{
NUFFIELD PROVINCIAL HOSPITALS TRUST
}

$\mathrm{T}$ HE Nuffield Provincial Hospitals Trust has published its sixth report, recording the progress of schemes described in the previous report and announcing new projects during the past three years. A wide range of activities has been supported, and 150 projects are listed under 15 general headings *.

In welcoming the Ministry of Health's entry into the field of providing finance for service and operational research, the Trustees note that "this policy is to be applauded and the competition it introduces will be stimulating. Of course, it does not follow that there will henceforth be an abundance of money available for the kind of study which indicates how health services can be made more effective, or whereby resources can be deployed in a better way. Yet the implication is that Britain is entering a period of more intensive scientific enquiry into its health services - surely a wise investment from which excellent dividends may be expected in the future". The Trust's own contribution to this investment during the period under review amounted to $£ 1,305,000$. During the period covered by the report 13 books have been published on sponsored research, and several other projects have resulted in reports published under other imprints.

The most important single new subject appearing in the report is postgraduate medical education. The Trustees' decision to allocate a large sum of money $(£ 308,750)$ to help promote schemes in the provinces has stimulated. a great deal of activity. The aim of the Trustees, to stimulate the development of a comprehensive national policy for the continuing education of doctors, and so lead to the improvement of medical-care services, seems in a fair way to being realized.

The following selection gives an indication of the range of the Trust's interests: A grant of $£ 20,000$ over five years was allocated to the Oxford Regional Hospital Board for

* The Nuffield Provincial Hospitals Trust. Sixth Report: A Record of the Progress of Schemes and Descriptions of New Projects 1961-1964. Pp. 152 (London: The Nuffield Provincial Hospitals Trust, 1964.) operational research studies of a number of aspects of hospital problems. $£ 5,000$ went to the United Birmingham Hospitals for a survey of health services for children in the City of Birmingham, and $£ 1,000$ to the University of Nottingham for a study on recruitment to, employment of, and demand for, certain of the professions supplementary to medicine; physiotherapy, occupational therapy, dietetics, orthoptics, and radiography. $£ 2,400$ over two years was made available for the secondment of a nurse to work in the Casualty Department of the General Infirmary at Leeds to investigate the cause and prevention of accidents in the home.

The North-Eastern Regional Hospital Board, Scotland, received a grant of $£ 50,000$ for the building of an in-patient and day hospital unit for child psychiatry in Aberdeen, and to cover the first year's running costs. The Aberdeen area, the report states, is particularly suitable for a project of this kind "in view of the basic demographic knowledge already available about the area, the close integration between the hospital service and the university department in mental health, the presence of an active research organization and the contacts already established with the local health and education authorities". $£ 12,000$ has been allocated for the provision of a parents' hostel at Smith's Hospital, Henley-on-Thames, which has facilities for some fifty psychotic or severely disturbed children. It has been found that little success attends efforts to treat these children unless the staff work very closely with the children's parents, particularly the mothers, since the corner-stone of treatment is the restoration or encouragement of this relationship. To an increasing extent the child is treated through the mother, because only rarely can anyone else give the necessary time and individual attention to bring about the return of the child to his or her normal position in the family.

A grant of $£ 4,000$ was allocated in order to make possible a study of community mental health services in Devonshire, the main purpose of which is to discover the problems and difficulties experienced by patients who have been 
mentally ill and received hospital treatment but who have now returned to live in the community. The Department of Psychological Medicine, University of Edinburgh, has been granted $£ 15,725$ over three years to develop a psychiatric treatment service for alcoholics, while $\mathfrak{f} 100,000$ has been reserved for the development of a health centre at Witney, near Oxford: "All the general practitioners of the town will practise from surgeries in the centre, which will also provide accommodation for local health authority and dental clinics and consultant outpatient clinics, as well as X-ray and pathological facilities run by the Oxford Regional Hospital Board."

A further allocation of $£ 92,250$ has been made to the Hospital Engineering Unit at the University of Glasgow to undertake a programme of research work concerning problems met in heating, ventilating and air-conditioning of hospitals, including the means of attaining proper standards of performance. Much of the practical work will be carried out in an experimental ward unit which the Scottish Homo and Health Department has built at
Hairmyres Hospital, East Kilbride, Glasgow, but research will also be carried out at other hospitals. Another project concerning the physical problems of hospital design involves the allocation of $£ 15,000$ to the United Oxford Hospitals and the Oxford Regional Hospital Board jointly to enable a special unit to be built at the Churchill Hospital, Oxford, in which experiments can be conducted into the lay-out of wards and departments and where equipment and procedures can be tested.

$£ 35,000$ has been ear-marked for an experimental intensive-care unit which has now been opened at Broadgreen Hospital, Liverpool. The report comments that the successes claimed for progressive patient care in the United States have won adherents in Britain for the persuasive principles involved. However, there has been little practical experience of the system or of any of its stages in Britain, although experiments and investigations in the care of acutely ill patients, and management of post-operative cases, have always been a feature of Britain's hospitals.

\section{SMOKELESS AIR}

$\mathrm{T}$ HE autumn issue of the quarterly Journal of the National Society for Clean Air (35, No. 131; 1964, Jondon) opens with some appropriate lines: "Ships, towers, domes, theatres and temples lie Open unto the fields, and to the sky; All bright and glittering in the smokeless air". This obviously epitomizes the aims of this organization, which have to-day become a mattor of international concern.

Only a few decades ago the United Kingdom and the United States were the only countries actively organized to combat air pollution in big industrial cities, whoro the problem of contamination of the air breathed, in its progressively toxic aspects, had become a matter of both general and medical concern. "Today we find organization, investigation, research and legislation in many countries and in every continent . . . the natural result of the tide of industrialization flowing from the North Atlantic countries to almost every corner of tho globe."

Progross of the movement since the early pioneer days is clearly revealed in the current number of the Journal, which contains a full first-hand report of the Council of Europo's Clean Air Conference at Strasbourg (June-July 1964). This has been described as the most comprehensive and longest event evor held on the problems of air pollution. Just previously, on the initiative of the Air Pollution Control Association of America, with the help of the U.S. Public Health Service, a meeting of six national air pollution organizations, including the United Kingdom, was convened and held at Washington, June 1964. The Strasbourg conference rovealed not only what 14 member countries (including observers from the United States) had in common in air pollution problems, how different national situations determined procedure but, equally, despite the impracticable measure of uniformity in law and administration, the strong desire towards what is modestly described as 'harmonization' of mutual activities.

Fundamentally, at least in some parts of the United Kingdom, probably just as portinent oversoas, much deponds on the availability and price of smokeless fucls. especially for domestic consumption; the position is not. satisfactory at the present timo, taking an overall survey, on either count. But air pollution is not only a question of utilization of smokeless solid fuel. As is well known, the Ministry of Transport in Britain has for some time been conducting a drive against smoke emitted by incorrectly maintained Diesel-engined vehicles using our public highways. The much-publicized national chocks on some of the worst offenders have already had a disciplinary value, but, as another article in the Journal points out, the policy advocated by the Society is: ". . . that offenders should be required to put their vehicles in good order and that they should be prohibited from operating until this was done. This . . . is a better and more certain incentive to good practice than purely punitive measures".

Smokeless air, even better, pure air, as an onvironment in which both to live and to work, may be an ideal, perhaps unattainable in heavily built-up and industrialized areas, but at least the problom is a live one in most civilized countries to-day, and the organization responsible for this publication is doing great service in co-ordinating the efforts of overyone concerned in reaching the ultimate goal in Britain.

\section{TRANSPLANTING MATURE DATE PALMS IN IRAQ}

$\mathrm{T}$ HERE is nothirg very unusual nowadays in the transplanting of large trees for particular purposes. It is done in towns where the immediate offect of a large tree is required for amenity reasons and to save the wastage and delay in time brought about by the vandalism to which young trees are somotimes subjected in urban areas. So long as the special equipment is available, and the expense can be met, the operation has justified itself in the success it has had in temperate climates where advantage is taken of the dormant season of the trees, but it is a different matter in a hot climato where tho rate of transpiration is one of the factors increasing the difficulty of the opcration.

Mr. R. H. Nocton, an agronomist spocializing in tropical agriculturo, has recently propared a paper describing the transplanting of 87 mature date palms in Iraq. The site was the New University of Baghdad and the trees ranged from 30 to $60 \mathrm{ft}$. in height. The operation was completely successful, and the following points are of particular interest. 